\title{
Hemisincarpia e nectário apendicular enfocados através de ontogênese floral em Mandevilla velame (A. St.-Hil.) Pichon, Apocynoideae ${ }^{1}$
}

\author{
SUELI MARIA GOMES ${ }^{2,4}$, LUIZA SUMIKO KINOSHITA ${ }^{3}$ e MARÍLIA DE MORAES CASTRO ${ }^{3}$
}

(recebido: 4 de outubro de 2007; aceito: 17 de janeiro de 2008)

\begin{abstract}
Hemisyncarpy and appendicular nectary approached by floral ontogeny of Mandevilla velame (A. St.-Hil.) Pichon, Apocynoideae). Mandevilla velame (A. St.-Hil.) Pichon is a subshrub with a peculiar albo-lanuginose indument and white showy flowers. The meaning of this work is to contribute for the morphologic knowledge of this species. Developmental stages of their flowers had been registered in scanning electron microscopy - SEM. Sepals initiation is unidirectional spiraled dextrorse, composing the quincuncial aestivation. The petals and staminal primordia initiated in a pentagonal dome. Before the closure of the corolla, their lobes overlap in imbricate dextrorse aestivation. The staminal primordia are initially presented as convex-rounded domes, later they become ovate and filament elongates by intercalate growth. The gynoecium formed is hemisyncarpic with a congenitally connate base. It is argued on the mixed origin of the gynoecium and the "secondary apocarpy" pointed out for the family is questioned and a new ontogenetic pattern is proposed. The nectary is appendicular, it being constituted of a ring deeply pentalobed and congenitally adnate to the ovary. This result differs from that one related for the other specie of this genus. Methodological adaptations for SEM studies are presented.
\end{abstract}

Key words - Apocynaceae, Macrosiphonia, "Cerrado", gynoecium, syncarpy

RESUMO - (Hemisincarpia e nectário apendicular enfocados através de ontogênese floral em Mandevilla velame (A. St.-Hil.) Pichon, Apocynoideae). Mandevilla velame (A. St.-Hil.) Pichon é um subarbusto com peculiar indumento albo-lanoso e flores vistosas brancas. Objetivando contribuir para o conhecimento morfológico desta espécie, estádios de desenvolvimento de suas flores foram documentados em microscopia eletrônica de varredura - MEV. Constatou-se que a iniciação das sépalas é unidirecional, espiralada dextrorsa, compondo a prefloração quincuncial. Os primórdios das pétalas e dos estames iniciam-se num domo pentagonal. Antes da corola se fechar, seus lobos se sobrepõem em prefloração imbricada dextrorsa. Os primórdios estaminais apresentam-se inicialmente como domos convexo-arredondados, depois se tornam ovais e os filetes tomam forma por crescimento intercalar. O gineceu formado é hemisincárpico com uma base congenitamente conata. Discute-se sobre a origem mista do gineceu, questiona-se a "apocarpia secundária" apontada para a família e propõe-se um novo padrão ontogenético. O nectário é apendicular, sendo constituído por um anel profundamente pentalobado congenitamente adnato ao ovário. Este resultado difere do que é referido para outra espécie do gênero. Adaptações metodológicas para estudos em MEV são apresentadas.

Palavras-chave - Apocynaceae, Macrosiphonia, Cerrado, gineceu, sincarpia

\section{Introdução}

Mandevilla Lindl. está circunscrita em Mesechiteae, Apocynoideae, Apocynaceae sensu lato - s.l. (Endress \& Bruyns 2000). Análises filogenéticas desta tribo (Simões et al. 2004, Simões et al. 2006b) e o preceito de monofiletismo fundamentaram a proposição de

1. Parte da Tese de Doutorado da primeira autora, Programa de PósGraduação em Biologia Vegetal da Universidade Estadual de Campinas.

2. Universidade de Brasília, Departamento de Botânica, Campus Universitário Darcy Ribeiro, Asa Norte, Caixa Postal 04457, 70910-970 Brasília, DF, Brasil.

3. Universidade Estadual de Campinas, Departamento de Botânica, Rua Monteiro Lobato 970, Cidade Universitária "Zeferino Vaz", Barão Geraldo, Caixa Postal 6109, 13083-970 Campinas, SP, Brasil.

4. Autor para correspondência: smgomes@unb.br
Macrosiphonia Müll. Arg., Quiotania Zarucchi e Telosiphonia (Woodson) J. Henrickson como sinônimos de Mandevilla (Simões et al. 2007), retomando em linhas gerais a classificação proposta por Pichon (1948a). Entre as mudanças nomenclaturais acima, a espécie que foi objeto do presente estudo, Macrosiphonia velame Müll. Arg., voltou a ser sinonimizada em Mandevilla velame (A. St.-Hil.) Pichon.

Grande parte da literatura sobre Mandevilla velame está associada nomenclaturalmente a Macrosiphonia velame, conhecida popularmente como velame-branco, que está entre as mais citadas como recurso medicinal nativo do cerrado (Guarim-Neto \& Morais 2003). Infusões das folhas, ramos e látex deste subarbusto são preconizadas contra úlcera, gastrite, doenças venéreas, eczemas na pele e queimaduras (Vila-Verde et al. 2003, Macedo \& Ferreira 2004). Mandevilla velame ocorre 
em Goiás, Distrito Federal, Minas Gerais, São Paulo e Rio Grande do Sul, sendo que as características distintivas para esta espécie incluem o indumento denso-lanoso que reveste toda a planta e suas folhas concolores (Simões \& Kinoshita 2002, Kinoshita 2005).

As espécies de Mandevilla geralmente possuem gineceu súpero, com dois carpelos livres em quase toda a extensão do ovário e conatos distalmente, numa condição intermediária entre a apocarpia e a sincarpia, de modo semelhante ao que ocorre na maioria das espécies de Apocynaceae s.l. A gradação da conação carpelar não está contemplada nas descrições taxonômicas desta família, as quais não comportam muito bem a explicação morfológica sobre este caráter, sendo que nas chaves de identificação (Badini 1967, Joly 1977, Freire 1983, Barroso 1991) acaba-se por optar por mais de uma entrada para Apocynaceae sensu stricto - s.s.

Desde Linnaeus (1753), a abordagem sobre os gêneros desta família tem sido contraditória. Este autor considerou o gineceu destas plantas ora constituído por um só elemento, ora por dois, colocando gêneros ora na Divisão Pentandria Monogynia, ora na Pentandria Digynia. De modo similar, Adanson (1768) distinguiu suas "Apocina" em gêneros com "um ou dois ovários".

Não há espécies de Apocynaceae s.l. que apresentem os carpelos totalmente livres, sendo que a conação carpelar está presente ao menos na cabeça do estilete. Depreende-se da literatura contemporânea que a qualificação da apocarpia em Apocynaceae s.s. ou s.l. refere-se aos carpelos livres apenas na região do ovário (Endress 1989, Gomes \& Cavalcanti 2001, Sennblad \& Bremer 2002, Simões \& Kinoshita 2002), mas mesmo nesta região há gradações de conação. A morfologia peculiar do gineceu tem levado os estudiosos do grupo a contradições do tipo "os dois carpelos são apocárpicos mas unidos no ápice" (Morales 1998), ou que "a cabeça do estilete desenvolve-se a partir da fusão posgênita do ápice do gineceu totalmente apocárpico" (Lipow \& Wyatt 1999), quando apocarpia significa carpelos livres (Hickey \& King 2002), cada qual com seu estilete simples (Fahn 1990).

Estes fatos evidenciam que o gineceu necessita ser melhor investigado do ponto de vista morfológico nesta família, especialmente sob a ótica da ontogênese floral. Alguns estudos ontogenéticos trataram sobre flores de espécies de Apocynaceae s.l. (Payer 1857, Boke 1948, 1949, Walker 1975) ou especificamente sobre o gineceu sincárpico destas plantas (Fallen 1985), mas representantes de Mesechiteae ainda não foram contemplados por este tipo de abordagem.

Espécies de Mandevilla, inclusive sob a denominação de Macrosiphonia, foram citadas em estudos sobre vascularização floral (Woodson Jr. \& Moore 1938) e sobre coléteres calicinais (Appezzato-Da-Glória \& Estelita 2000, Simões et al. 2006a). A anatomia de flores de Macrosiphonia petraea (A. St.-Hil.) K. Schum. (=Mandevilla petraea (A. St.-Hil.) Pichon) foi examinada por Galetto (1997), que relacionou as características morfológicas desta espécie com sua biologia floral.

O tipo de gineceu encontrado em Mandevilla velame está presente na maioria das espécies de Apocynaceae s.l. e seu estudo pode contribuir para o conhecimento morfológico da família como um todo. O presente trabalho objetivou documentar os estádios mais precoces do desenvolvimento floral de Mandevilla velame, enfatizando-se o estudo ontogenético do gineceu.

\section{Material e métodos}

Ramos portando botões florais e flores adultas de Mandevilla velame foram fixados em FAA - formalina: ácido acético: etanol na proporção 1:1:18 (Johansen 1940) imediatamente após a coleta. Posteriormente, trocou-se a solução fixadora e as amostras foram submetidas a uma bomba de vácuo por $24 \mathrm{~h}$, desidratadas em etanol $50 \%$ por $24 \mathrm{~h}$ e estocadas em etanol 70\%. Exsicatas testemunhas do material usado: BRASIL. Distrito Federal: Brazlândia, 19/I/2003, S.M. Gomes 505 e 508. (UEC 142034 e 142037); Brasília, Parque Ecológico Norte, Asa Norte, 20/I/2003, S.M. Gomes 510 (UEC 142039). Fotografou-se a planta no campo e a secção longitudinal - SL - de sua flor foi ilustrada em nanquim por Ricardo de Azevedo Lourenço.

O procedimento geral usado em microscopia eletrônica de varredura - MEV (Bozzola \& Russel 1991) - foi adaptado, resultando no protocolo aqui descrito. Os botões florais estocados em etanol $70 \%$ foram isolados e dissecados sob estereomicroscópio Olympus S7H10, com pinças de ponta fina (pinças de relojoeiro), agulhas hipodérmicas e uma ferramenta confeccionada, o pincel monocerda. As peças isoladas foram mantidas em etanol $70 \%$. Testou-se a desidratação diretamente em etanol 95\% (Mansano et al. 2002), bem como gradientes de etanol 80-90-100\%, por $1 \mathrm{~h}$, $2 \mathrm{~h}$ e $24 \mathrm{~h}$, optando-se pela desidratação gradativa e mais demorada. Após a desidratação etílica, os botões foram dispostos em cestas de fundo telado, sempre se manuseando os mesmos sob etanol absoluto. As cestas foram colocadas na evaporadora Balzers, obtendo-se o ponto crítico de secagem com dióxido de carbono líquido, no Laboratório de Microscopia Eletrônica (LME) da Universidade Estadual de Campinas - UNICAMP.

As amostras desidratadas foram fixadas nos cilindros ("stubs") de alumínio com fita carbono "Carbon Adhesive Leit". Procedeu-se à metalização na evaporadora ("sputter coater") Balzers Bal-Tec SCD 050, com 16 nm de espessura de filme de ouro. O filme do metal depositado na região superior dos botões roliços foi conectado ao cilindro de alumínio com pequenos pedaços de fita carbono. Os espécimes 
foram armazenados em mini-câmaras dessecadoras constituídas por frascos pequenos e abertos mantidos dentro de outro maior e tampado, contendo uma camada de sílica-gel no fundo. Examinou-se o material no aparelho Jeol 5900LV, sob voltagem entre 5-25 kV, no Laboratório de Microscopia Eletrônica do Laboratório Nacional de Luz Síncrotron.

As observações foram documentadas através de imagens digitalizadas salvas em arquivos "bitmap" e editadas em softwares específicos ("MGI Photo Suite" e "Adobe Photoshop 7.0”) visando sua padronização.

\section{Resultados}

Mandevilla velame apresenta flores brancas, pentâmeras, com o tubo corolino longo e estreito na base (figuras 1,2). As anteras são oblongo-lineares e férteis apenas na metade distal, com a base estéril adnata à cabeça do estilete; o filete é geniculado (figura 2). Os dois carpelos são conatos, exceto em uma porção do ovário.

A ontogênese floral de $M$. velame encontra-se documentada em seus estádios mais precoces (figuras
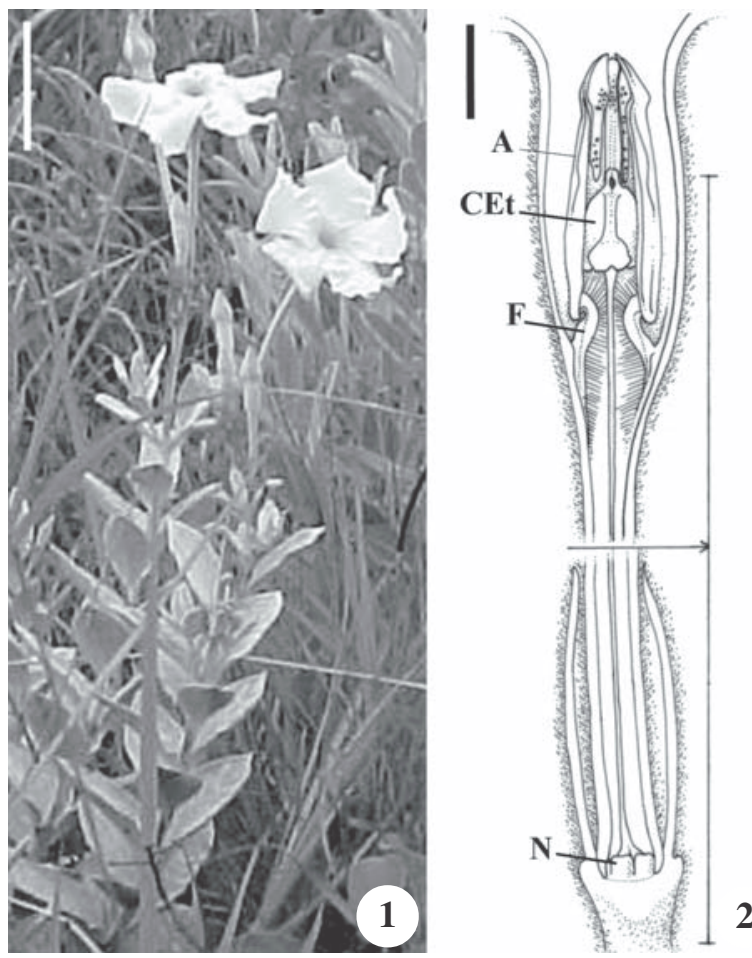

Figuras 1-2. Mandevilla velame: planta no campo (1) e flor adulta (2, SL): antera (A) longa, filete (F) geniculado, cabeça do estilete $(\mathrm{CEt})$ pentangulada e nectário $(\mathrm{N})$ profundamente lobado. Barras $=5 \mathrm{~cm}(1) ; 5 \mathrm{~mm}(2)$.

Figures 1-2. Mandevilla velame: plant in the field (1) and adult flower (2, SL): long anther (A), geniculate filament $(\mathrm{F})$, pentangulate style head (CEt) and deeply lobate nectary $(\mathrm{N})$. Bars $=5 \mathrm{~cm} \mathrm{(1);} 5 \mathrm{~mm}(2)$.
3-18). Pares de bractéolas decussadas entre si e com coléteres em posição estipular (figura 3) protegem os botões florais. A iniciação das sépalas é assíncrona, unidirecional, espiralada e dextrorsa (figuras $4 ; 5$ ), constituindo a prefloração quincuncial. O indumento densamente lanoso do cálice (figura 2) desenvolve-se precocemente; cedo a sépala $\mathrm{S} 1$ apresenta tricomas (figura 4), que estão presentes inclusive na face adaxial das sépalas (figura 13), entremeando os coléteres opositissépalos (figura 18). Os primórdios das pétalas iniciam-se nos vértices do domo pentagonal e alternos a estes se formam os dos estames (figura 6). O tubo corolino origina-se a partir de uma região congenitamente conata (figuras 10, >; 11, 13, 17). As lacínias se sobrepõem antes da corola se fechar em prefloração imbricada contorta dextrorsa (figura 7). Os estames iniciam-se arredondados (figura 6) e tornam-se ovais (figuras 10, 13); a antera desenvolve uma região distal fértil (figura $17, \rightarrow$ ), que se posiciona acima da cabeça do estilete (figura 2), e outra basal e estéril, que constitui a asa da antera (figuras 14, 16-17); o filete origina-se congenitamente adnato ao tubo corolino (figura 17) e sua porção livre recurva-se, formando um genículo (figura 2). A iniciação do gineceu se dá a partir de um domo anelar com uma concavidade (figuras 7-8, $\rightarrow$ ), constituído pelos carpelos congenitamente conatos (figuras 7-9,*), que se diferencia no centro do botão floral; em seus bordos formam-se dois primórdios carpelares (figuras 9-10, 12-13, $\rightarrow$ ). A região conata congenitamente possui $60 \mu \mathrm{m}$ de altura (figura $9, *$ ), quando os dois primórdios carpelares recém surgiram. Cada primórdio carpelar cresce individualmente (figuras 9-10) e fecha-se (figura 10), formando seu respectivo lóculo e originando o ovário (figura 12). A porção distal dos carpelos alonga-se (figuras 13-14) e fusiona-se distalmente (figura $14, \star$ ), restando uma região no ovário em que os carpelos permanecem livres (figuras 14, 17, $\downarrow$ ), constituindo o gineceu hemisincárpico de origem mista com ovário súpero. A cabeça do estilete alarga-se (figuras 15-17) e o estilete forma-se por crescimento intercalar (figuras 16-17). Os primórdios do nectário originam-se congenitamente unidos à base ovariana (figuras 14-15), na altura em que os carpelos estão congenitamente conatos (figuras 14-15, *); há continuidade histológica entre os carpelos e o nectário (figura 16); na flor em antese, o anel nectarífero apresenta-se profundamente lobado (figura 2).

\section{Discussão}

A iniciação assíncrona, unidirecional e espiralada das sépalas em espécies de Apocynaceae s.l. foi registrada por Payer (1857), que estudou a ontogênese 

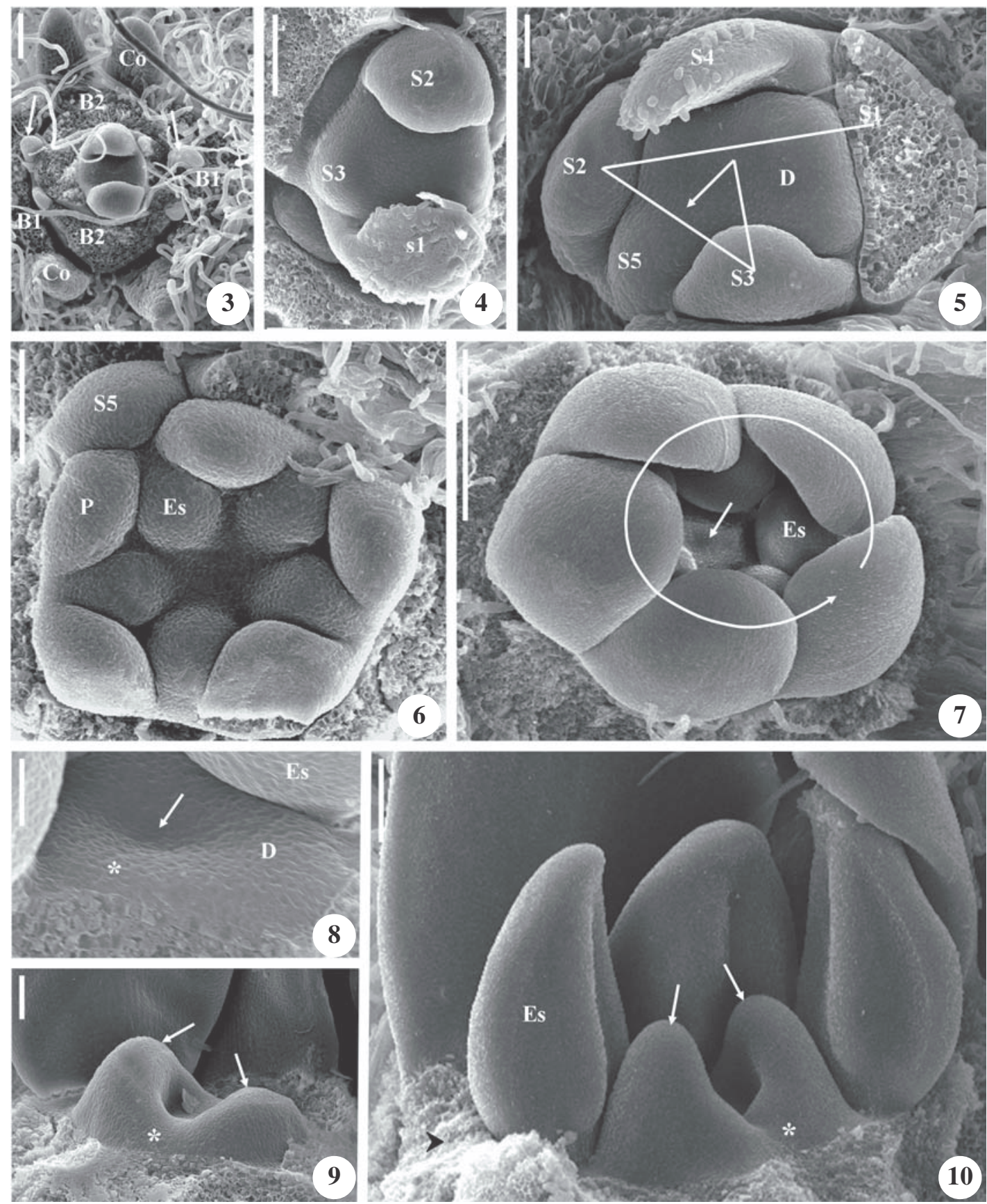

Figuras 3-10. Mandevilla velame: ontogênese floral I. 3. Pares de bractéolas (B) com coléteres (Co) e seus primórdios (setas) em posição estipular. 4-5. Iniciação dextrorsa (seta) das sépalas (S1 a S5) e domo (D) pentagonal. 6. Primórdios das pétalas $(\mathrm{P})$ e dos estames (Es). 6-8, 10. Formação dos estames (Es). 7, 10. Corola: prefloração dextrorsa (7, seta curva); região do tubo conata congenitamente $(10,>)$. 7-10. Gineceu: domo $(8, \mathrm{D})$ anelar de iniciação e concavidade no centro (7-8, seta); região de conação carpelar congênita (8-10, *); primórdios carpelares (9-10, setas). 3-10: S.M. Gomes 505. Barras = 100 $\mu \mathrm{m}(3-6,10) ; 200 \mu \mathrm{m}(7) ; 50 \mu \mathrm{m}(8-9)$.

Figures 3-10. Mandevilla velame: floral ontogenesis I. 3. Pairs of bracteoles (B, removed) with colleters (Co) and their colleters primordia (arrows) in stipulate position. 4-5. Dextrorse initiation (arrow) of sepals (S1 to S5) and pentagonal dome (D). 6. Petals (P) and staminal (Es) primordia. 6-8, 10. Staminal (Es) formation. 7, 10. Corolla: dextrorse prefloration (7, arched arrow); congenitally connate tube region $(10,>)$. 7-10. Gynoecium: initiation ring dome $(8, \mathrm{D})$ and central concavity (7-8, arrow); congenitally connate carpellary region (8-10,*); carpels primordia (9-10, arrows). 3-10: S.M. Gomes 505. Bars = $100 \mu \mathrm{m}(3-6,10) ; 200 \mu \mathrm{m}(7) ; 50 \mu \mathrm{m}(8-9)$. 

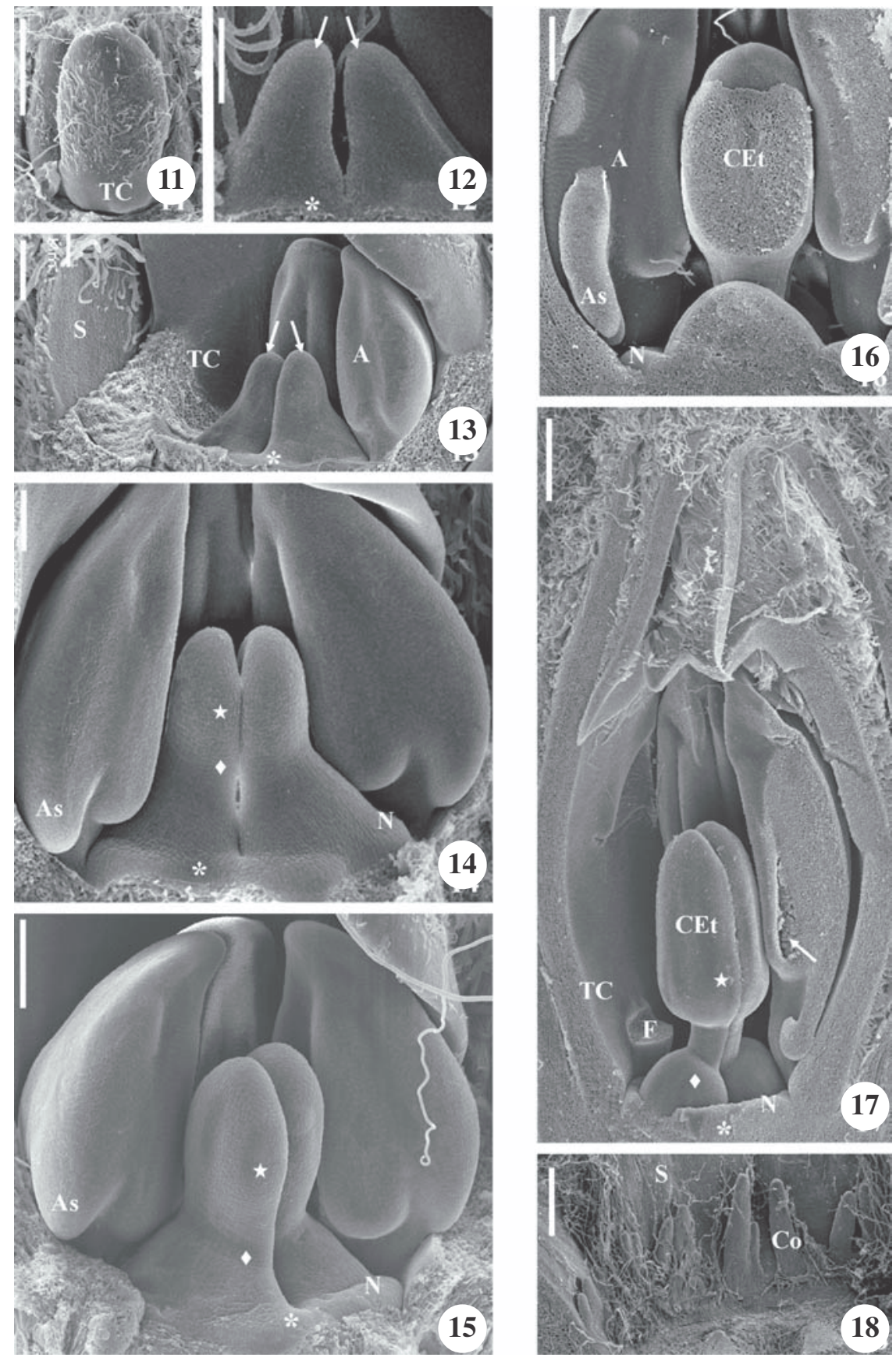

Figuras 11-18. Mandevilla velame: ontogênese floral II. 11, 13, 17. Tubo da corola (TC). 12-17. Gineceu: primórdios carpelares $(12-13$, setas); regiões conatas congênita $(12-15, *)$ e posgenitamente $(14-15,17, \star)$ e região dos carpelos livres (14-15, 17, $)$; cabeça do estilete (16-17, CEt). 13-17. Antera: formação da asa (14-16, As); pólen (17, seta); filete (17, F). 14-17. Nectário (N): primórdios (14), etapas de desenvolvimento (15-17) e continuidade entre carpelo e nectário (16). 18. Flor adulta (verticilos internos removidos): coléteres opositissépalos e tricomas na base do cálice. 11, 13-16: S.M. Gomes

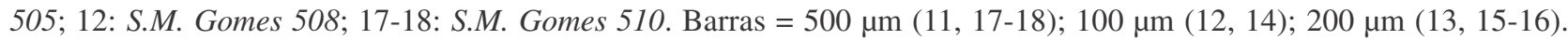

Figures 11-18. Mandevilla velame: floral ontogenesis II. 11, 13, 17. Corolla tube (TC). 12-17. Gynoecium: carpel primordia (12-13, arrows); congenitally $(12-15, *)$ and posgenitally $(14-15,17, \star)$ connate regions and free carpellary region (14-15, 17, ); style head (16-17, CEt). 13-17. Anther: wing formation (14-16, As); pollen (17, arrow); filament (17, F). 14-17. Nectary $(\mathrm{N})$ : primordia (14), developmental stages (15-17) and continuity between carpel and nectary (16). 18. Adult flower (internal verticilles removed): antisepalous colleters and trichomes in the calyx base. 11, 13-16: S.M. Gomes 505; 12: S.M. Gomes 508; 17-18: S.M. Gomes 510. Bars = $500 \mu \mathrm{m}(11,17-18) ; 100 \mu \mathrm{m}(12,14) ; 200 \mu \mathrm{m}(13,15-16)$. 
floral de Apocynum cannabinum L. e Asclepias syriaca L. As ilustrações primorosas desta obra clássica permitem identificar estas características ontogenéticas calicinais, que foram aqui descritas para Mandevilla velame. Este tipo de iniciação no cálice redunda na prefloração quincuncial, que é muito frequiente entre as angiospermas.

O sentido de iniciação das sépalas é dextrorso em $M$. velame (figuras 3-5) e coincide com o da prefloração de sua corola (figuras 7,11), tal como ocorre com $A$. cannabinum (Payer 1857), que pertence à mesma subfamília. Isto pode representar uma tendência unidirecional entre cálice e corola que precisa ser investigada em outros representantes da família.

A assincronia na iniciação das sépalas e sua disposição espiralada no receptáculo não impedem que as mesmas desenvolvam uma conação basal, resultando em uma gamossepalia rudimentar (figura 18). Esta gamossepalia não alcança grandes extensões no cálice, possivelmente porque envolve a conação congênita tardia de sépalas situadas em duas séries distintas. Leins \& Erbar (1997) apontaram que a conação entre verticilos pressupõe sua origem verticilada, ou seja, sua iniciação a partir do mesmo nó, mas isto não ocorre na formação do cálice em $M$. velame, onde claramente os primórdios das sépalas iniciam-se de modo espiralado e a partir de diferentes alturas no receptáculo floral.

Existe uma controvérsia na literatura quanto à fusão no cálice em Apocynaceae s.s. Espécies desta família são descritas em obras taxonômicas como gamossépalas (Ezcurra 1981a, Sakane \& Shepherd 1986, Simões \& Kinoshita 2002, Kinoshita 2005) ou dialissépalas (Souza \& Lorenzi 2005). Estudos morfológicos não esclareceram plenamente esta questão, já que para Woodson Jr \& Moore (1938) a gamossepalia está presente na maioria das 60 espécies por eles examinadas, enquanto que o estudo de anatomia floral feito por Allorge (1976) para 25 gêneros de Apocynaceae s.s. aponta que a maioria é dialissépala, com alguns táxons gamossépalos bem na base. Estudo anatômico mais detalhado é necessário para esclarecer se a gamossepalia é um caráter presente em toda a família ou predominante em algumas espécies, como aquela aqui estudada.

Os coléteres calicinais constituem fileiras situadas logo acima da região de conação das sépalas (figura 18) e são do tipo séssil. Estas emergências secretoras estão presentes na maioria dos gêneros de Apocynaceae s.l., ocorrendo também em ramos vegetativos, em posição variável nas folhas e nós caulinares (Endress \& Bruyns 2000, Simões \& Kinoshita 2002), inclusive em outras angiospermas, tendo sido interpretadas como estípulas vestigiais (Glück 1919 apud Woodson Jr. \& Moore 1938).
Uma possível correlação entre a posição dos coléteres calicinais e nodais foi proposta por Woodson Jr. \& Moore (1938), que associaram a presença destas emergências em posição opositissépala com aquela intrapeciolar em ramos vegetativos de Macrosiphonia (=Mandevilla), entre outros gêneros. A hipótese levantada por estes autores foi questionada por Simões \& Kinoshita (2002), que observaram que este tipo de correlação não se estabelece em várias espécies de Apocynaceae s.s., estando presente apenas em Macrosiphonia (=Mandevilla), Prestonia e Rhodocalyx, evidenciando que as observações de Woodson Jr. \& Moore (1938) constituem exceções e não um padrão consistente para toda a família.

A presença de tricomas na face adaxial das sépalas (figura 18) é uma característica pouco freqüente em Apocynaceae s.l. e constitui um caráter distintivo entre as espécies de Aspidosperma (Gomes \& Cavalcanti 2001), o que deveria ser analisado também para Mandevilla. Tricomas situados junto aos coléteres calicinais (figura 18) são igualmente incomuns. Uma hipótese a ser investigada é se tais tricomas são apenas tectores ou se desempenham alguma função secretora, que eventualmente pode ser auxiliar ou complementar à dos próprios coléteres.

A iniciação dos primórdios corolinos é síncrona em M. velame (figura 6). A sincronia intraverticilos florais é tida como uma formação semelhante à de órgãos verticilados (Leins \& Erbar 1997, Prenner 2004) e esta interpretação se aplica plenamente para a corola da espécie estudada. A sincronia intraverticilos florais pode ser entendida como o resultado de um encurtamento dos internós entre as pétalas que as tornou cíclicas ao longo da evolução. É possível que esta sincronia tenha relação com o domo pentagonal e achatado que precede a formação da corola (figuras 5-6), o qual também pode estar contribuindo para o posterior crescimento intercalar que origina a região congenitamente conata do tubo corolino (figura $10,>$ ). Domo claramente convexo anterior à iniciação corolina é encontrado em plantas dialipétalas, como Theaceae (Tsou 1998) e Luxemburgia schwackeana Taub., Ochnaceae (Amaral \& Bittrich 1998).

A despeito de sua iniciação síncrona, os lobos da corola se expandem lateralmente e acabam por apresentar uma sobreposição de suas margens (figura 7), resultando na prefloração imbricativa contorta dextrorsa (figura 11). Este tipo de prefloração, segundo Ezcurra (1981a), está presente em todas as Echitoideae (= Apocynoideae sensu Endress \& Bruyns 2000).

Os primórdios estaminais formam-se alternipétalos (figura 6) e com os filetes adnatos congenitamente ao tubo corolino (figuras 13,17 ), de modo semelhante ao 
observado por Payer (1857) em Apocynum cannabinum e Asclepias syriaca. Este padrão também foi descrito para as 60 espécies de Apocynaceae s.s. analisadas em sua vascularização floral por Woodson Jr. \& Moore (1938). O desenvolvimento basípeto do estame é identificado pela diferenciação inicial da antera (figura 6), seguida pela formação da porção livre do filete (figuras 10,13-14) através de crescimento intercalar, constituindo um padrão de desenvolvimento do androceu presente em outras espécies desta família (Payer 1857, Boke 1949).

A antera de $M$. velame cedo desenvolve uma projeção basal estéril (figura 10) que constitui a asa (figuras 2, 14, 16-17). Esta estrutura anteral está presente em diferentes espécies de Apocynoideae e Asclepiadoideae, sendo-lhe atribuída a função de auxiliar no direcionamento do aparelho bucal do polinizador para que ele passe entre as duas anteras e ao longo de regiões específicas da cabeça do estilete (ver aurículas em Lipow \& Wyatt 1999, Tostes et al. 2003). A região estéril alcança cerca da metade do comprimento da antera na flor em antese de $M$. velame e posiciona-se acima da cabeça do estilete (figura 2).

Análises sobre graus de complexidade do androceu foram feitas por Fallen (1986) e Simões \& Kinoshita (2002), que apontaram para a importância taxonômica deste verticilo, concordando que Apocynoideae tem a maior diferenciação estaminal entre as Apocynaceae s.s. O presente trabalho possibilitou a documentação de estádios mais precoces de desenvolvimento da antera, onde não foram encontradas evidências de fusão posgênita entre as asas (figuras 10,13-15). Esta evidência sustenta que, ao menos no início do desenvolvimento, a longa região basal estéril na antera advém do crescimento intercalar das asas em conjunto com o conectivo, não envolvendo fusão entre antera e filete.

A formação do gineceu em $M$. velame envolve a participação de regiões de conação carpelar congênita (figuras 8-10, 12-15, 17, *) e posgênita (figuras 14-15, $17, \star)$. A fusão congênita tem sido referida como filogenética, enquanto que a posgênita seria ontogenética (Cusick 1966, Walker 1975, Fahn 1990, Gasser \& Robinson-Beers 1993). Essa equiparação não é seguida aqui, pois entende-se que os termos congênito/filogenético e posgênito/ontogenético não se equivalem. A fusão capelar congênita é um evento ontogenético e filogenético simultaneamente; no primeiro caso, porque ocorre ao longo do desenvolvimento do gineceu, durante a ontogênese floral. Igualmente, a fusão congênita constitui um evento filogenético, pois é uma variação morfológica que se desenvolveu ao longo da evolução de Apocynaceae. O mesmo se dá em relação à fusão posgênita.
Em $M$. velame, a conação posgênita só ocorre na porção distal dos carpelos, ou seja, ela é espacialmente restrita, conforme Walker (1975) qualificou para o desenvolvimento do gineceu em Catharanthus roseus (L.) G. Don. Engenhosa investigação ontogenética sobre a conação carpelar posgênita foi feita nesta última planta por Walker (1978), que removeu cirurgicamente um dos carpelos, tendo constatado que o carpelo remanescente desenvolveu-se de modo mais ou menos normal, exceto por uma redução dos tricomas na cabeça do estilete e ausência de colarinho na face carpelar adaxial. Com base na capacidade de um só carpelo continuar a se desenvolver, este autor concluiu que os eventos relativos à fusão posgênita teriam sido adicionados evolutivamente à ontogênese de um gineceu apocárpico (Walker 1978). Esta idéia precisa ser mais bem aprofundada, conforme discute-se adiante.

Walker (1975) relatou que um anel meristemático caracteriza a iniciação do gineceu em C. roseus, mas não aprofundou a discussão sobre esta região, que se assemelha àquela encontrada em $M$. velame (figuras 8-10, *). Esta região torna-se pouco conspícua com o desenvolvimento do gineceu (figuras 15, 17), mas pode ser identificada em secções anatômicas de flores adultas de Macrosiphonia petraea e Mandevilla pentlandiana (Galetto 1997), e em outras espécies de Apocynaceae s.l. estudadas morfologicamente (Fallen 1986, Lin \& Bernardello 1999), inclusive em abordagens ontogenéticas (Payer 1857, Boke 1949, Walker 1975, Endress et al. 1983). Ela é importante do ponto de vista morfológico e evolutivo, pois caracteriza a existência de um tipo de sincarpia nestas plantas, mas sua presença não foi discutida na literatura. A presença desta região congenitamente conata fragiliza a hipótese de Walker (1978) referente à origem deste tipo de gineceu a partir daquele apocárpico.

O início do desenvolvimento da região congenitamente conata do gineceu (figuras 8-9, *) assemelha-se à iniciação de carpelos ascidiados (ou ascidiformes) presente em plantas dialicarpelares, onde um meristema anelar origina uma região côncava, que forma um carpelo com as margens congenitamente suturadas desde sua iniciação, cujo formato lembra o de uma ascídia (Heel 1984). Não obstante, tal semelhança é apenas aparente, pois em $M$. velame o domo anelar (figuras 8-9, *) corresponde não a um carpelo suturado, mas a dois carpelos congenitamente conatos.

Esta região também pode ser comparada ao gineceu sinascidiado encontrado em algumas angiospermas (Olson 2003, Caris et al. 2006). Esta semelhança existe até o momento em que dois primórdios carpelares formam-se nos bordos desta região conata em $M$. velame 
(figuras 9-10, 12), desenvolvem-se individualmente (figura 13) e tornam-se plicados e conatos distalmente (figuras 14-17, $\star$ ). O gineceu em M. velame reúne características do gineceu sinascidiado e simplicado, em um padrão ontogenético que se propõe aqui que seja denominado simplicadoascidiado.

Como a sincarpia não é total ao longo do gineceu, pois a maior extensão do ovário permanece com os carpelos livres (figuras 14, 17, $)$ ), caracteriza-se assim uma hemisincarpia. Este termo foi utilizado por Markgraf (1979) para descrever os frutos que se formam unidos apenas na base, como em espécies de Ochrosia Juss. (Apocynaceae s.s.); já Ehrendorfer (1985) usou-o para descrever o gineceu de Apocynaceae s.s. e Asclepiadaceae (= Apocynaceae $s . l$.).

Tradicionalmente o ovário em Apocynaceae s.s. e Asclepiadaceae tem sido referido como apocárpico ou sincárpico (Woodson Jr. \& Moore 1938, Ezcurra 1981a). A presença de uma região congenitamente conata na base do ovário qualifica uma sincarpia parcial, referendando a propriedade do termo usado por Ehrendorfer (1985) e excluindo a caracterização deste tipo de gineceu como apocárpico. Propõe-se que este tipo de sincarpia seja denominado de origem mista, pois se forma devido à presença de regiões conatas congênita (figuras 8-10, *) e posgenitamente (figuras 14-15, 17, $\star$ ).

A "apocarpia secundária" apontada na literatura sobre Apocynaceae s.l. (Engler 1964, Cronquist 1981, Ezcurra 1981a, Allorge \& Couderc 1983, Fallen 1985, 1986) é questionável. A conação carpelar congênita na base do gineceu hemisincárpico evidencia que esta família não apresenta uma apocarpia que possa ser interpretada filogeneticamente como secundária, pois não se trata de uma apocarpia, mas de um tipo de sincarpia. A extensão da região conata na base do ovário é variável, o que ocorre inclusive dentro de um mesmo gênero, como é o caso de Rauvolfia, cujas espécies podem ter os carpelos unidos por apenas um ponto ou ao longo de quase todo o ovário (Markgraf 1984).

Esta interpretação difere daquela de Endress et al. (1983) que, tendo examinado flores antéticas e em estádios jovens em espécies hemisincárpicas de Sapindales, Malvales e Gentianales, concluiu que o gineceu é "claramente apocárpico", mesmo tendo reconhecido regiões basais conatas no ovário em Mitrasacme (Loganiaceae) e Mortoniella (Apocynaceae s.l.). Fallen (1985) apontou que a seleção natural teria favorecido o retorno à condição apocárpica em Apocynaceae s.s., mas, confirmando-se a presença generalizada desta região basal congenitamente conata nesta família, tem-se que a mesma não apresentaria uma reversão para apocarpia, mas ter-se-ia desenvolvido ao longo da evolução deste grupo um tipo peculiar de sincarpia - a hemisincarpia.

Por outro lado, Endress et al. (1983) apontaram que este tipo elaborado de gineceu reúne as vantagens da apocarpia com as da sincarpia. Cronquist (1993), discutindo sobre o papel ecológico da hemisincarpia ("apocarpia" secundária) ressaltou que a existência de uma região única e receptiva em comum entre os carpelos irmãos seria uma vantagem adaptativa, pois a deposição do pólen em qualquer uma das superfícies estigmáticas poderia resultar na fertilização dos óvulos de ambos ou de um só dos ovários separados. Endress $(1982,1998)$ destacou que a sincarpia distal nos carpelos em Apocynaceae s.l. resulta em um cômpito, que atua não só na distribuição como também na seleção dos tubos polínicos. A sincarpia nas angiospermas é uma vantagem adaptativa no sentido de que proporciona a distribuição dos tubos polínicos entre todos os carpelos após uma polinização bem sucedida. Identificam-se, assim, nas espécies de Apocynaceae s.l. hemisincárpicas, vantagens da apocarpia (formação de frutículos independentes a partir de carpelos do mesmo gineceu) e da sincarpia em um peculiar arranjo.

O desenvolvimento inicial do gineceu é acrópeto em M. velame, pois primeiro forma-se o ovário (figuras 9-10, 12), seguido pelo crescimento distal dos carpelos (figuras 13-15). Este padrão também está presente em outras espécies de Apocynaceae s.l. estudadas ontogeneticamente (Payer 1857, Boke 1949, Walker 1975, Fallen 1985) e em outras angiospermas (Endress et al. 1983, Decraene et al. 2002, Sutter \& Endress 2003), contrapondo-se à diferenciação inicial basípeta constatada no androceu.

Os carpelos fecham-se antes da conação distal entre os mesmos (figuras 12-14) e sem evidências da formação de óvulos até seu fechamento (figuras 9-10, 12), o que coaduna com estudos ontogenéticos feitos com outras espécies de Apocynaceae s.l. (Payer 1857, Boke 1949, Walker 1975, Fallen 1985) e outras angiospermas (Endress et al. 1983, Sutter \& Endress 2003). Já em Cyperaceae, a iniciação dos óvulos é bastante precoce e ocorre assim que se inicia o gineceu e muito antes do fechamento do ovário (Vrijdaghs et al. 2005a, b), acontecendo de modo semelhante em Restionaceae (Decraene et al. 2002). Análises sobre possíveis padrões temporais de formação do ovário e dos óvulos em angiospermas são desconhecidas; talvez tais padrões existam, o que requer ser mais bem investigado.

Os primórdios do nectário iniciam-se como emergências laterais na base congenitamente conata do gineceu (figuras 14-17), tendo sido observado continuidade 
entre seus tecidos (figura 16), caracterizando-se uma origem apendicular para esta estrutura secretora. Estes resultados se coadunam com os de Woodson Jr. \& Moore (1938), que incluíram duas espécies de Macrosiphonia em seu amplo estudo sobre vascularização floral de Apocynaceae s.s. Estes autores identificaram que os traços vasculares dos nectários estão claramente associados com os dos carpelos, concluindo que "os nectários são definitivamente apêndices e não hipertrofias do receptáculo" floral. Esta interpretação contraria a de Galetto (1997), que considerou o nectário em Macrosiphonia petraea (= Mandevilla petraea) como tendo origem receptacular; as ilustrações neste trabalho permitem identificar uma continuidade histológica entre carpelo e nectário, assim como os traços vasculares do nectário originando-se a partir dos carpelares.

O nectário em $M$. velame desenvolve-se até constituir um anel profundamente pentalobado congenitamente adnato ao ovário (figura 2, 16-17). Esta estrutura foi denominada de disco nectarífero em diferentes trabalhos sobre Apocynaceae s.s. (Woodson Jr. \& Moore 1938, Pichon 1948a, b, c, Allorge 1976, Ezcurra 1981a, Huber 1983, Sakane \& Shepherd 1986, Endress 1989, Middleton 1994, 1997, Judd et al. 1999, Morales 1999, Kinoshita 2005), mas seu formato assemelha-se mais ao de um anel, conforme descrito por alguns autores (Ezcurra 1981b, Zarucchi et al. 1995). É interessante notar que esta denominação de disco nectarífero para uma estrutura anelar na base do gineceu também ocorre em Convolvulaceae (Galetto \& Bernardello 2004), entre outras plantas.

O anel nectarífero constitui uma unidade congenitamente conata em $M$. velame e outras espécies de Apocynaceae s.s., mas é constituído por duas emergências alternicarpelares e independentes entre si em Vinca major L., Catharanthus roseus (L.) G. Don e Cabucala erythrocarpa (Vatke) Markgr. (Allorge 1976), assim como em outras espécies de Mandevilla (Simões \& Kinoshita 2002, Löhne et al. 2004), em uma variação morfológica bastante útil para a taxonomia destas plantas.

O surgimento dos verticilos florais é acrópeto (cálice, corola, androceu e gineceu, nesta ordem), como ocorre em espécies de Leguminosae (Klitgaard 1999), sendo esta uma característica usual para a maioria das angiospermas (Tucker 2003). Esta orientação não é seguida por estruturas como os coléteres e nectário, que se formam após a diferenciação do cálice e do gineceu, respectivamente.

Destaca-se que foi feita uma adaptação da metodologia usualmente empregada em MEV que se mostrou vantajosa sob vários aspectos. No presente trabalho, a fixação dos espécimes foi feita em FAA, mas em alguns estudos de morfologia vegetal relata-se o uso de glutaraldeído (Kolb \& Müller 2004, Valente \& Costa 2005, Machado et al. 2006) e pós-fixação em tetróxido de ósmio (Martins 2002, Procópio et al. 2003a, b, Araújo \& Matsuoka 2004, Endress 2005, Valente \& Costa 2005). Esta última substância é altamente tóxica, penetra através da pele, assim como por inalação ou ingestão e seu odor é difícil de ser percebido, em contraposição aos componentes do FAA, especialmente o formol e o ácido acético, que também são nocivos, mas são facilmente percebidos pelo odor. Desta forma, o FAA parece ser o fixador mais apropriado para este tipo de trabalho, devendo ser a primeira opção a ser considerada em estudos micromorfológicos. Há relatos de fixação de espécimes diretamente em etanol $70 \%$ (Endress 2005), ou mesmo em etanol 95\% (Tucker \& Bernhardt 2000), mas nem sempre este procedimento redunda em bons resultados, conforme nossa experiência com Apocynaceae s.l.

Em relação à desidratação dos espécimes, alguns solventes são preconizados entre os diferentes trabalhos, sendo mais comum o uso da acetona (Tsou 1998, Hayes et al. 2000, Mansano et al. 2002, Martins 2002, Litt \& Stevenson 2003, Vinckier \& Smets 2003, Galetto \& Bernardello 2004, Klein et al. 2004, Craene 2004, 2005), ou mesmo dimetoximetano (Decraene et al. 2002, Vrijdaghs et al. 2005a, b, Caris et al. 2006). Estas substâncias foram totalmente excluídas do protocolo desenvolvido no presente trabalho. O único solvente utilizado foi o etanol, que se revelou um meio mais vantajoso no processo de desidratação por ser menos agressivo à cutícula epidérmica vegetal e por ser mais barato, além de não possuir restrições legais para sua aquisição, enquanto que a acetona é mais agressiva, mais cara e de uso controlado no país, pois pertence à lista de substâncias sob controle do Ministério da Justiça (ANVISA 2006).

A desidratação rápida com etanol (1 h ou 2 h em cada concentração) ocasionalmente produziu enrugamento na superfície de alguns materiais mais tenros, enquanto que o uso de gradiente etanólico por $24 \mathrm{~h}$ em cada concentração mostrou-se mais adequado. O processo de desidratação consiste em substituir a água do citoplasma celular através da difusão do etanol, que posteriormente é substituído por dióxido de carbono líquido, para ser submetido ao ponto crítico. Se este processo for muito rápido, o contato com concentrações etanólicas mais elevadas pode ocasionar deformações na parede celular, que resultam em enrugamento, especialmente em meristemas florais. A necessidade de desidratação mais prolongada pode ser devido a especificidades dos tecidos das plantas aqui estudadas em comparação com espécies de outras famílias. 
Não foram encontrados relatos sobre como armazenar o material desidratado ao ponto crítico, para o quê desenvolveu-se a mini-câmara dessecadora relatada. $\mathrm{O}$ frasco maior foi mantido fechado até o momento de se efetuar as observações em MEV, possibilitando um armazenamento por cerca de um mês. Os estádios ontogenéticos puderam ser observados sem que se tenha verificado reidratação dos espécimes.

Após a metalização, estruturas roliças, tais como botões em vista lateral, podem não apresentar a necessária continuidade entre o filme de ouro e a fita carbono, devido à falta de deposição do metal embaixo da estrutura, gerando imagens "carregadas" eletronicamente. Este tipo de problema foi solucionado colocando-se "pontes" de fita carbono na beirada do espécime, em pontos de menor importância, conforme os objetivos do trabalho. Isto estabeleceu uma continuidade condutora entre a camada de ouro superior depositada sobre os espécimes e o suporte metálico, constituído pelo cilindro de alumínio, contribuindo para a geração de imagens de boa qualidade.

No presente trabalho, procurou-se contribuir para o conhecimento morfológico de Apocynaceae s.l., especificamente de Mandevilla velame, que é uma planta com importância medicinal (Guarim-Neto \& Morais 2003, Vila-Verde et al. 2003, Macedo \& Ferreira 2004). Por outro lado, ressalta-se aqui o potencial paisagístico desta espécie, cujas qualidades ornamentais residem não só em suas vistosas flores longo-tubulosas e brancas, com fauce amarela (figura 1), mas também em seu caule e folhas, devido ao peculiar indumento albo-lanoso, frequientemente cinéreo, deste subarbusto. Este potencial ainda está por ser explorado, pois estas plantas carecem de domesticação.

Agradecimentos - As autoras agradecem à FAPESP, pelo Auxílio Pesquisa, ao LNLS, pela infra-estrutura disponibilizada e ao CNPq, pela Bolsa de Doutorado concedida à primeira autora e pela Bolsa de Produtividade em Pesquisa concedida à segunda autora.

\section{Referências bibliográficas}

ADANSON, M. 1768. Familles des plantes. (Reimp. 1966. Introdução de F.A. Stafleu.) Ed. Lehre, Paris.

ALLORGE, L. 1976. Morphologie et biologie florales des Apocynacées - applications taxonomiques. Thése de École Pratique des Hautes Études, Paris.

ALLORGE, L. \& COUDERC, H. 1983. La syncarpi chez Tabernanthe et sa particularité dans la sous-famille des Tabernaemontanoideae (Apocynaceae). Bulletin du Muséum National d'Histoire Naturelle, Paris, 4a série, 5, section B, Adansonia 2:223-236.
AMARAL, M.C.E. \& BITTRICH, V. 1998. Ontogenia inicial do androceu de espécies de Ochnaceae subfam. Sauvagesioideae através da análise em microscopia eletrônica de varredura. Revista Brasileira de Botânica 21:269-273.

ANVISA - Agência Nacional de Vigilância Sanitária/ Ministério da Saúde. 2006. Resolução-RDC № 12, de 30/01/2006. Atualiza o Anexo I da Portaria SVS/MS № 344, de 1998 - Listas de Substâncias Entorpecentes, Psicotrópicas, Precursoras e outras sob Controle Especial. DOU - Diário Oficial da União 26(supl.):4. Brasília, 6 de fevereiro de 2006.

APPEZZATO-DA-GLÓRIA, B. \& ESTELITA, M.E.M. 2000. Development, structure and distribution of colleters in Mandevilla illustris and M. velutina (Apocynaceae). Revista Brasileira de Botânica 23:113-120.

ARAUJO, J.C.A. de \& MATSUOKA, K. 2004. Histopathology of the interaction between Alternaria solani and resistant and susceptible tomato plants. Fitopatologia Brasileira 29:268-275.

BADINI, J. 1967. Chaves para Botânica Sistemática. Universidade Federal de Ouro Preto/Escola de Farmácia, Ouro Preto.

BARROSO, G.M. 1991. Sistemática de angiospermas do Brasil. LTC/EDUSP, São Paulo.

BOKE, N.H. 1948. Developmental of the perianth in Vinca rosea L. American Journal of Botany 35:413-423.

BOKE, N.H. 1949. Development of the stamens and carpels in Vinca rosea L. American Journal of Botany 36:535547.

BOZZOLA, J.J. \& RUSSEL, L.D. 1991. Electron microscopy - principles and techniques for biologists. Jones \& Batlett Pub., Boston.

CARIS, P.L., GEUTEN, K.P., JANSSENS, S.B. \& SMETS, E.F. 2006. Floral development in three species of Impatiens (Balsaminaceae). American Journal of Botany 93:1-14.

CRAENE, L.P.R. 2004. Floral developmenta of Berberidopsis corallina: a crucial link in the evolution of flowers in the core Eudicots. American Journal of Botany 94:741-751.

CRAENE, L.P.R. 2005. Floral developmental evidence for the systematic position of Batis (Bataceae). American Journal of Botany 92:752-760.

CRONQUIST, A. 1981. An integrated system of classification of flowering plants. Allen Press Inc., Lawrence.

CRONQUIST, A. 1993. The evolution and classification of flowering plants. The New York Botanical Garden, New York.

CUSICK, F. 1966. On phylogenetic and ontogenetic fusions. In Trends in plant morphogenesis (E.G. Cutter). John Wiley \& Sons, New York, p.170-183.

DECRAENE, L.P.R., LINDER, H.P. \& SMETS, E.F. 2002. Ontogeny and evolution of the flowers of South African Restionaceae with special emphasis on the gynoecium. Plant Systematics and Evolution 231:225-258. 
EHRENDORFER, F. 1985. Sinopsis del reino vegetal: espermatófitos. In Tratado de Botânica (E. Strasburger). Ediciones Omega, Barcelona, p.757-914.

ENDRESS, M.E. 1989. Novelties in South American Malouetia (Apocynaceae). Annals of the Missouri Botanical Garden 76:1141-1147.

ENDRESS, M.E. \& BRUYNS, P.V. 2000. A revised classification of the Apocynaceae s.l. Botanical Review (Lancaster) 66:1-56.

ENDRESS, P.K. 1982. Syncarpy and alternative modes of escaping disadvantages of apocarpy in primitive angiosperms. Taxon 31:48-52.

ENDRESS, P.K. 1998. Diversity and evolutionary biology of tropical flowers. (Cambridge Tropical Biology Series). Cambridge University Press, Cambridge.

ENDRESS, P.K. 2005. Carpels in Brasenia (Cabombaceae) are completely ascidiate despite a long stigmatic crest. Annals of Botany 96:209-215.

ENDRESS, P.K., JENNY, M. \& FALLEN, M.E. 1983. Convergent elaboration of apocarpous gynoecia in higher advanced dicotyledons (Sapindales, Malvales, Gentianales). Nordic Journal of Botany 3:293-300.

ENGLER, A. 1964. Syllabus der pflanzenfamilien. Gebrüder Bortraeger, Berlin.

EZCURRA, C. 1981a. Revisión de las Apocináceas de la Argentina. Darwiniana 23:367-474.

EZCURRA, C. 1981b. Novedades en los generos Temnadenia y Macrosiphonia (Apocynaceae). Hickenia 45:241-246.

FAHN, A. 1990. Plant anatomy. $3^{\text {th }}$ ed. Pergamon Press, Oxford

FALLEN, M.E. 1985. The gynoecial development and systematic position of Allamanda (Apocynaceae). American Journal of Botany 72:572-579.

FALLEN, M.E. 1986. Floral struture in the Apocynaceae: morphological, functional, and evolutionary aspects. Botanische Jahrbücher für Systematik 106:245-286.

FREIRE, C.V. 1983. Chaves Analíticas: para a determinação das famílias das plantas pteridófitas, gimnospermas e angiospermas brasileiras ou exóticas cultivadas no Brasil. Coleção Mossoroense, vol. CCC. CNPq/Fundação Guimarães Duque/Escola Superior de Agricultura de Mossoró, Mossoró.

GALETTO, L. 1997. Flower structure and nectar chemical composition in three Argentine Apocynaceae. Flora 192:197-207.

GALETTO, L. \& BERNARDELLO, G. 2004. Floral nectaries, nectar production dynamics and chemical composition in six Ipomoea species (Convolvulaceae) in relation to pollinators. Annals of Botany 94:269-280.

GASSER, C.S. \& ROBINSON-BEERS, K. 1993. Pistil development. Plant Cell 5:1231-1239.

GOMES, S.M. \& CAVALCANTI, T.B. 2001. Morfologia floral de Aspidosperma Mart \& Zucc. (Apocynaceae). Acta Botanica Brasilica 15:73-88.
GUARIM-NETO, G. \& MORAIS, R.G. 2003. Recursos medicinais de espécies do cerrado de Mato Grosso: um estudo bibliográfico. Acta Botanica Brasilica 17:561-584.

HAYES, V., SCHNEIDER, E.L. \& CARLQUIST, S. 2000. Floral development of Nelumbo nucifera (Nelumbonaceae). International Journal of Plant Sciences 151(6 Suppl.): S183-S191.

HEEL, W.A.V. 1984. Variation in the development of ascidiform carpels, an S.E.M.-investigation. Blumea 29:443-452.

HICKEY, M. \& KING, C. 2002. The Cambridge illustrated glossary of botanical terms. Cambridge University Press, Cambridge (reimpr. de 2000).

HUBER, H. 1983. Apocynaceae. In A revised handbook to the flora of Ceylon (M.D. Dassanayake, ed.). A.A. Balkema, Rotterdam, v.4, p.25-72.

JOHANSEN, D.A. 1940. Plant microtechnique. McGraw-Hill, New York.

JOLY, A.B. 1977. Botânica: chaves de identificação das famílias de plantas vasculares que ocorrem no Brasil baseadas em chaves de Franz Thonner. Ed. Nacional, São Paulo.

JUDD, W.S., CAMPBELL, C.S., KELLOGG, E.A. \& STEVENS, P.F. 1999. Plant systematics: a phylogenetic approach. Sinauer Associates, Sunderland.

KINOSHITA, L.S. (coord.) 2005. Apocynaceae. In Flora Fanerogâmica do Estado de São Paulo (M.G.L. Wanderley, G.J. Shepherd, T.S. Melhem \& Giulietti, A.M., orgs.). FAPESP/HUCITEC., São Paulo, v.4, p.35-36.

KLEIN, D.E., GOMES, V.M., SILVA-NETO, S.J. da \& CUNHA, M. 2004. The structure of colleters in several species of Simira (Rubiaceae). Annals of Botany 94:733-740.

KLITGAARD, B.B. 1999. Floral ontogeny in tribe Dalbergieae (Leguminosae: Papilionoideae): Dalbergia brasiliensis, Machaerium villosum s.l. Platymiscium floribundum, and Pterocarpus rotundifolius. Plant Systematics and Evolution 219:1-25.

KOLB, D. \& MÜLLER, M. 2004. Light, conventional and environmental scanning electron microscopy of the trichomes of Cucurbita pepo subsp. pepo var. styriaca and histochemistry of glandular secretory products. Annals of Botany 94:515-526.

LEINS, P. \& ERBAR, C. 1997. Floral developmental studies: some old and new questions. International Journal of Plant Sciences 158(6-Suppl.):S3-S12.

LIN, S. \& BERNARDELLO, G. 1999. Flower structure and reproductive biology in Aspidosperma quebrachoblanco (Apocynaceae), a tree pollinated by deceit. International Journal of Plant Sciences 160:869-878.

LINNAEUS, C. 1753. Species plantarum. A facsimile of the first edition, 2 vol. 1957. Ray Society, London.

LIPOW, S.R. \& WYATT, R. 1999. Self-incompatibility in Apocynum cannabinum. Plant Systematics and Evolution 219:99-109. 
LITT, A. \& STEVENSON, D.W. 2003. Floral development and morphology of Vochysiaceae. I. The structure of the gynoecium. American Journal of Botany 90:15331547.

LÖHNE, C., MACHADO, I.C., POREMBSKI, S., ERBAR, C. \& LEINS, P. 2004. Pollination biology of a Mandevilla species (Apocynaceae), characteristic of NE-Brazilian inselberg vegetation. Botanische Jahrbücher für Systematik 125:229-243.

MACEDO, M. \& FERREIRA, A.R. 2004. Plantas medicinais usadas para tratamentos dermatológicos, em comunidades da Bacia do Alto Paraguai, Mato Grosso. Revista Brasileira de Farmacognosia 14(Supl.1):40-44.

MACHADO, S.R., GREGÓRIO, E.A. \& GUIMARÃES, E. 2006. Ovary peltate trichomes of Zeyheria montana (Bignoniaceae): developmental ultrastructure and secretion in relation to function. Annals of Botany 97:357-369.

MANSANO, V.F., TUCKER, S.C. \& TOZZI, A.M.G.A. 2002. Floral ontogeny of Lecointea, Zollernia, Exostyles, and Harleyodendron (Leguminosae: Papilionoideae: Swartzieae s.l.). American Journal of Botany 89:15531569.

MARKGRAF, F. 1979. Flora malesianae praecursores LIX. Apocynaceae V. Ochrosia, Neisosperma. Blumea 25: 233-247.

MARKGRAF, F. 1984. Flora malesianae praecursores LXIV. Apocynaceae VI. Rauvolfia. Blumea 30:157-167.

MARTINS, M.B.G. 2002. Estudos de microscopia óptica e de microscopia eletrônica de varredura em folhas de Mentha spicata e de Mentha spicata x suaveolens (Lamiaceae). Bragantia 61:205-218.

MIDDLETON, D.J. 1994. A revision of Ichnocarpus (Apocynaceae). Blumea 39:73-94.

MIDDLETON, D.J. 1997. A revision of Carruthersia Seemann (Apocynaceae). Blumea 42:489-498.

MORALES, J.F. 1998. A synopsis of the genus Mandevilla (Apocynaceae) in Mexico and Central America. Brittonia 50:214-232.

MORALES, J.F. 1999. A synopsis of the genus Odontadenia: series of revisions of Apocynaceae XLV. Bulletin du Jardin Botanique National de Belgique 67:381-477.

OLSON, M.E. 2003. Ontogenetic origins of floral bilateral symmetry in Moringaceae (Brassicales). American Journal of Botany 90:49-71.

PAYER, J.B. 1857. Traité d'organogénie comparée de la fleur. In Historiae Naruralis Classica. Wheldon \& Wesley Ltd., Codicote, Herts (Reimp. 1966), v. XLCII.

PICHON, M. 1948a. Classification des Apocynacées: I. PICHON Carissées et Ambélaniées. Mémoires du Museum National d'Histoire Naturelle 24:111-181.

PICHON, M. 1948b. Classification des Apocynacées: IX. Rauvolfiées, Alstoniées, Allamandées et Tabernémontanoidées. Mémoires du Museum National d'Histoire Naturelle 27:153-254.
PICHON, M. 1948c. Classification des Apocynacées: XIX. Le rétinacle des Echitoïdées. Bulletin de la Société Botanique de France 95:211-216.

PRENNER, G. 2004. Floral ontogeny in Lespedeza thunbergii (Leguminosae: Papilionoideae: Desmodieae): variations from the unidirectional mode of organ formation. Journal of Plant Research 117:297-302.

PROCÓPIO, S.O., FERREIRA, E.A., SILVA, E.A.M., SILVA, A.A., RUFINO, R.J.N. \& SANTOS, J.B. 2003a. Estudos anatômicos de folhas de espécies de plantas daninhas de grande ocorrência no Brasil. III - Galinsoga parviflora, Crotalaria incana, Conyza bonariensis e Ipomoea cairica. Planta Daninha 21: 1-9.

PROCÓPIO, S.O., FERREIRA, E.A., SILVA, E.A.M., SILVA, A.A. \& RUFINO, R.J.N. 2003b. Estudos anatômicos de folhas de espécies de plantas daninhas de grande ocorrência no Brasil. V - Leonurus sibiricus, Leonotis nepetaefolia, Plantago tomentosa e Sida glazioviii. Planta Daninha 21:403-411.

SAKANE, M. \& SHEPHERD, G.J. 1986. Uma revisão do gênero Allamanda L. (Apocynaceae). Revista Brasileira de Botânica 9:125-149.

SENNBLAD, B. \& BREMER, B. 2002. Classification of Apocynaceae s.l. according to a New Approach Combining Linnean and Phylogenetic Taxonomy. Plant Systematics and Evolution 51:389-409.

SIMÕES, A.O. \& KINOSHITA, L.S. 2002. The Apocynaceae s. str. of the Carrancas region, Minas Gerais, Brazil. Darwiniana 40:127-169.

SIMÕES, A.O., ENDRESS, M.E., NIET, T.V.D., KINOSHITA, L.S. \& CONTI, E. 2004. Tribal and intergeneric relationships of Mesechiteae (Apocynoideae, Apocynaceae): evidence from three noncoding plastid DNA regions and morphology. American Journal of Botany 91:1409-1418.

SIMÕES, A.O., CASTRO, M.M. \& KINOSHITA, L.S. 2006a. Calycine colleters of seven species of Apocynaceae (Apocynoideae) from Brazil. Botanical Journal of the Linnean Society 152:387-398.

SIMÕES, A.O., ENDRESS, M.E., VAN-DER-NIET, T., KINOSHITA L.S. \& CONTI, E. 2006b. Is Mandevilla (Apocynaceae, Mesechiteae) monophyletic? Evidence from five plastid DNA loci and morphology. Annals of the Missouri Botanical Garden 93:565-591.

SIMÕES, A.O., KINOSHITA, L.S. \& ENDRESS, M.E. 2007. New Combinations in Mandevilla Lindley (Apocynaceae). Novon 17:87-90.

SOUZA, V.C. \& LORENZI, H. 2005. Botânica sistemática: guia para identificação das famílias de angiospermas da flora brasileira, segundo A.P.G.II. Plantarum, Nova Odessa.

SUTTER, D.M. \& ENDRESS, P.K. 2003. Female flower and cupule structure in Balanopaceae, an enigmatic Rosid family. Annals of Botany 92:459-469. 
TOSTES, R.B, VIEIRA, M.F. \& CAMPOS, L.A. 2003. Polinização de Peltastes peltatus (Vell.) Woodson (Apocynoideae, Apocynaceae) por abelhas euglossíneas. In Apoideae Neotropica: homenagem aos 90 anos de Jesus Santiago Moure (G.A.R. Melo \& I. Alves-dosSantos). UNESC, Criciúma.

TSOU, C.-H. 1998. Early floral development of Camellioideae (Theaceae). American Journal of Botany 85:1531-1547.

TUCKER, S.C. 2003. Update on floral development - floral development in Legumes. Plant Physiology 131:911926.

TUCKER, S.C. \& BERNHARDT, P. 2000. Floral ontogeny, pattern formation, and evolution in Hibbertia and Adrastaea (Dilleniaceae). American Journal of Botany 87:1915-1936.

VALENTE, M. da C. \& COSTA, C.G. 2005. Estudo anatômico da flor de Marsdenia loniceroides E. Fournier (Asclepiadoideae - Apocynaceae). Rodriguésia 56:51-66.

VILA-VERDE, G.M., PAULA, J.R. \& CANEIRO, D.M. 2003. Levantamento etnobotânico das plantas medicinais do cerrado utilizadas pela população de Mossâmedes (GO). Revista Brasileira de Farmacognosia 13(supl.):64-66.

VINCKIER, S. \& SMETS, E. 2003. Morphological and ultrastructural diversity of orbicules in Gentianaceae. Annals of Botany 92:657-672.
VRIJDAGHS, A., CARIS, P., GOETGHEBEUR, P. \& SMETS, E. 2005a. Floral ontogeny in Scirpus, Eriophorum and Dulichium (Cyperaceae), with special reference to the perianth. Annals of Botany 95:1199-1209.

VRIJDAGHS, A., GOETGHEBEUR, P., MUASYA, A.M, CARIS, P. \& SMETS, E. 2005b. Floral ontogeny in Ficinia and Isolepis (Cyperaceae), with focus on the nature and origin of the gynophore. Annals of Botany 96:1247-1264.

WALKER, D.B. 1975. Postgenital carpel fusion in Catharanthus roseus (Apocynaceae). I. Light and scanning electron microscopic study of gynoecial ontogeny. American Journal of Botany 62:457-467.

WALKER, D.B. 1978. Postgenital carpel fusion in Catharanthus roseus (Apocynaceae). IV. Significance of the fusion. American Journal of Botany 65:119-121.

WOODSON JR., R.E. \& MOORE, J.A. 1938. The vascular anatomy and comparative morphology of apocynaceous flowers. Bulletin of the Torrey Botanical Club 65:135169.

ZARUCCHI, J.L., MORILLO, G.N., ENDRESS, M.E., HANSEN, B.F. \& LEEUWENBERG, A.J.M. Apocynaceae. 1995. In Flora of the Venezuelan Guayana (P.E. Berry, B.K. Holst \& K. Yatskievych). Missouri Botanical Garden, St. Louis, v.2, p.471-571. 